\title{
PRODUÇÃO DE BIODIESEL A PARTIR DO ÓLEO DE FRITURA: UMA ALTERNATIVA SUSTENTÁVEL.
}

\author{
M. A. C. BUMBA ${ }^{1}$, R. K.OI ${ }^{2}$ e H. YAMAMURA ${ }^{3}$ \\ ${ }^{1}$ Universidade Católica de Santos, Departamento de Engenharia de Produção \\ ${ }^{2}$ Universidade Católica de Santos, Departamento de Engenharia de Produção \\ ${ }^{3}$ Universidade Católica de Santos, Departamento de Química Tecnológica \\ E-mail para contato: marcoacb@unisantos.br
}

\begin{abstract}
RESUMO - Com o crescimento da demanda energética e utilização de combustíveis não renováveis, surge a necessidade de substituí-los por recursos à partir da logística reversa, utilizando matrizes energéticas que poluam menos o meio ambiente. Neste trabalho, buscou-se desenvolver a produção do biodiesel à partir de óleos residuais de fritura como uma alternativa sustentável e economicamente viável. A síntese é eficaz e ambientalmente correta, já que os óleos alimentícios são na maioria das vezes destinados no solo e redes de esgoto. O método utilizado foi a reação de transesterificação, no qual o óleo de fritura após prévio tratamento, reage com hidróxido de sódio em metanol, produzindo o biodiesel. $\mathrm{O}$ método é uma alternativa viável de logística reversa, já que utilizou-se como matéria prima o óleo residual da cantina universitária. Pretende-se com estudos complementares, avaliar a viabilidade de utilização do biodiesel no gerador elétrico da Universidade, completandose o ciclo de utilização dentro da própria instituição.
\end{abstract}

\section{INTRODUÇÃO}

Atualmente, a matriz energética mundial é fortemente dependente do petróleo e seus derivados, e também de outras fontes não renováveis de energia como o carvão, que causam grandes problemas como a poluição do ar, mudanças climáticas e formação de resíduos tóxicos. Assim, é necessário uma crescente demanda de pesquisas e desenvolvimento de novas tecnologias relacionadas a fontes alternativas de energia. Outra justificativa para estas pesquisas é considerarmos que as principais matrizes energéticas utilizadas atualmente são limitadas e esgotando-se em um futuro próximo, aliadas ao grande impacto no meio ambiente, com consequências econômicas, tecnológicas, sociais, etc. (PARENTE, 2003).

Porém, apesar de muitas pesquisas e avanços em tecnologias relacionadas as matrizes renováveis de energia, muitos autores ainda questionam a capacidade das referidas matrizes suprirem todos os requisitos necessários para se tornarem realmente sustentáveis (LIMA, 2004). Desta forma, a substituição de fontes de energia clássicas pelas fontes renováveis, deve ocorrer de forma gradativa, levando-se em consideração os mais variados detalhes sob os pontos de vista estratégico, técnico, econômico e ambiental. No caso quando a fonte de energia utiliza matérias primas de origem vegetal, 


\section{9 a 22 de outubro de 2014 \\ Florianópolis/SC}

deve-se considerar também a necessidade de se controlar e viabilizar o equilíbrio no desenvolvimento agrícola do país (PIGHINELLI, 2007).

O crescente desenvolvimento social, econômico e tecnológico, agregado ao aumento populacional, resulta em um enorme consumo energético e consequente aumento de poluição. Desta forma, justifica-se também a busca por fontes energéticas de menor impacto ambiental. Uma das tecnologias alternativas mais promissoras é a utilização de biodiesel como combustível, que demonstra ser uma fonte viável de energia renovável, em substituição ao óleo diesel e outros derivados de petróleo.

\subsection{Biodiesel}

Biodiesel é uma denominação abrangente de combustíveis e aditivos provenientes de fontes renováveis. Um combustível que pode ser utilizado em substituição ao diesel comum, sem proporcionar danos mecânicos ao equipamento, além de possuir desempenho de igual qualidade em relação à potência, rendimento, etc.

O Biodiesel permite um ciclo fechado de dióxido de carbono, uma vez que o mesmo é absorvido pela planta enquanto ela cresce e posteriormente é liberado na combustão do motor. Levando-se em consideração estes fatores e outros correlatos, pode-se avaliar que o custo empreendido tecnologicamente para a produção do Biodiesel é irrelevante em relação aos benefícios proporcionados pela sua utilização (PARENTE, 2003). Importante ressaltar que o biodiesel não é só um produto nascido da necessidade de adaptações ou reciclagem. É um combustível de qualidade que pode ser utilizado em qualquer motor a diesel, com pouca ou nenhuma necessidade de adaptação, por vezes demonstrando desempenho até superior ao combustível padrão (DIAS, 2007).

Nos grandes centros urbanos, uma opção atraente para a produção do biodiesel são os óleos residuais de fritura, matéria prima abundante constituída principalmente de resíduos de óleo de soja, que representam aproximadamente $90 \%$ da produção de óleos comestíveis no Brasil.

\subsection{Biodiesel à partir de óleos residuais de frituras.}

Atualmente, como não há uma legislação específica para o descarte de óleos residuais, muitos estabelecimentos descartam o óleo de fritura de forma inadequada, como por exemplo na rede de esgoto. Tal forma de descarte, resulta no entupimento de tubulações e consequente utilização de produtos químicos para desentupir as tubulações, produtos estes que são tóxicos e ocasionam danos ambientais juntamente com o óleo.

Ao ser despejado nas redes de esgotos comuns, o óleo acaba indo parar em rios e lençóis freáticos entre outros habitats aquáticos. Esta ação é um problema de grande proporção, pois segundo BILCK et al (2009), um litro de óleo despejado no esgoto, tem capacidade de poluir cerca de um milhão de litros de água, quantidade suficiente para o consumo de uma pessoa durante 14 anos.

Porém, apesar dos danos ocasionados pela geração desses resíduos, é plenamente possível reverter este quadro através da utilização de mais de 30.000 toneladas de óleo de fritura gerados anualmente 
(PARENTE, 2003). Atualmente no país, a reutilização de óleo de fritura se concentra basicamente na produção de sabão e biodiesel, e em menor proporção nos setores de fabricação de tintas e massas de vidraceiro (NOGUEIRA e BEBER, 2009).

Há três vantagens principais de se utilizar óleos residuais de frituras como matéria prima para a produção de biodiesel: a) no âmbito tecnológico, com a não necessidade do processo de extração do óleo; b) no âmbito econômico, devido à diminuição do custo da matéria prima com o resíduo de fritura; c) no âmbito ambiental, pois destina-se adequadamente um resíduo que em geral é descartado inadequadamente no meio ambiente.

Desta forma, o presente trabalho teve como objetivo desenvolver um estudo de viabilidade técnica de produção de biodiesel à partir de óleo de fritura residual utilizado na cantina da Universidade Católica de Santos - UNISANTOS, através de uma reação de transesterificação. Como justificativa, pode-se citar a redução dos impactos ambientais causados pelo descarte inadequado do óleo de fritura através do conceito de engenharia reversa, com o reaproveitamento ou destinação de resíduos em ciclos produtivos, com a produção de um combustível de alto valor energético e baixo custo.

\subsection{Reação de transesterificação.}

A produção completa de biodiesel através da transesterificação envolve as etapas de preparação de matéria prima, reação, separação de fases, purificação dos ésteres e da glicerina, conforme mostra a figura 1:

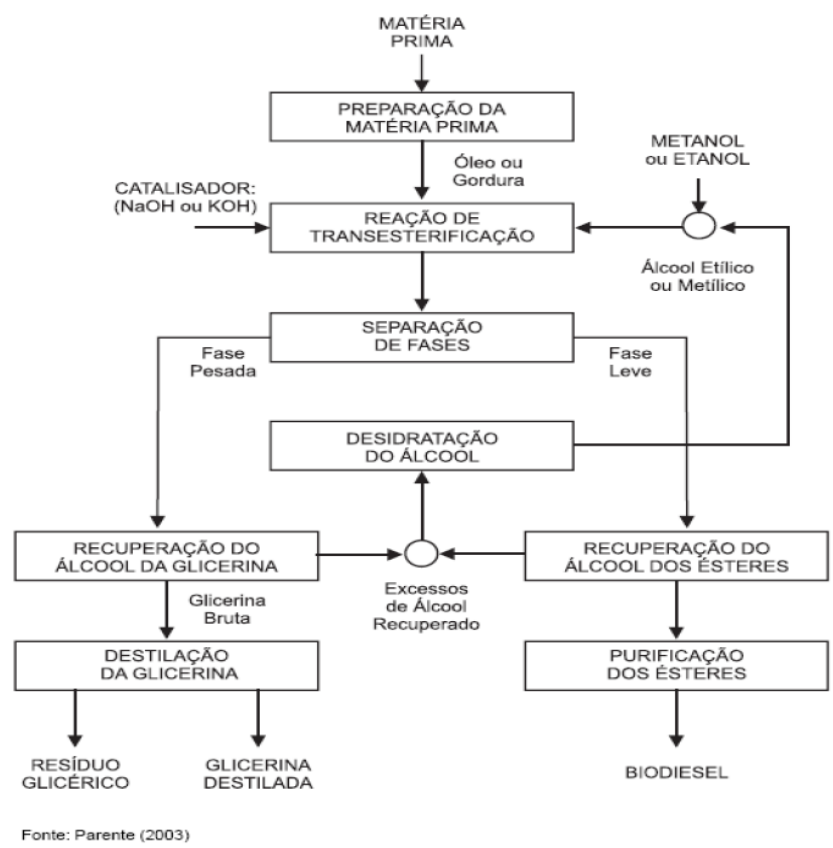

Figura 1: Etapas da preparação do biodiesel.

A transesterificação é um processo químico de grande aplicabilidade industrial e também amplamente utilizada para a produção de ésteres alquílicos de ácidos graxos (biodiesel). Conforme 
mostra a figura 2, na reação de transesterificação o triglicerídeo reage com um álcool simples (metanol ou etanol), formando ésteres (metílico ou etílico) que constituem o biodiesel e o glicerol como subproduto:

\begin{tabular}{|c|c|c|c|}
\hline Triglicerídeo & Metanol & $\Rightarrow$ Biodiesel & ol \\
\hline $\mathrm{O}$ & & $\mathrm{O}$ & \\
\hline $\begin{array}{c}\mathrm{H}_{2} \mathrm{C}-\mathrm{O}-\mathrm{C}-\mathrm{R}_{1} \\
\mathrm{O}\end{array}$ & $3 \mathrm{CH}_{3} \mathrm{OH}$ & $\begin{array}{c}\mathrm{H}_{3} \mathrm{C}-\mathrm{O}-\mathrm{C}-\mathrm{R}_{1} \\
\mathrm{O}\end{array}$ & $\underset{\mid}{\mathrm{H}_{2} \mathrm{C}}-\mathrm{OH}$ \\
\hline $\begin{array}{c}\mathrm{HC}-\mathrm{O}-\mathrm{C}-\mathrm{R}_{2} \\
\mathrm{O}\end{array}$ & & $\begin{array}{c}\mathrm{H}_{3} \mathrm{C}-\mathrm{O}-\mathrm{C}-\mathrm{R}_{2} \\
\mathrm{O}\end{array}$ & $\mathrm{HC}-\mathrm{OH}$ \\
\hline $\mathrm{H}_{2} \mathrm{C}-\mathrm{O}-\mathrm{C}-\mathrm{R}_{3}$ & & $\mathrm{H}_{3} \mathrm{C}-\mathrm{O}-\mathrm{C}-\mathrm{R}_{3}$ & $\mathrm{H}_{2} \mathrm{C}-\mathrm{OH}$ \\
\hline
\end{tabular}

Figura 2 - Reação de transesterificação (SOLOMONS, 2002)

\section{MATERIAIS E MÉTODOS.}

\subsection{Coleta e preparo da amostra do óleo de fritura.}

O óleo residual utilizado nesta pesquisa mostrado na figura 3, foi coletado na cantina da Universidade, e posteriormente filtrado para remover os sólidos em suspensão provenientes do processo de fritura, antes de sua utilização no processo.

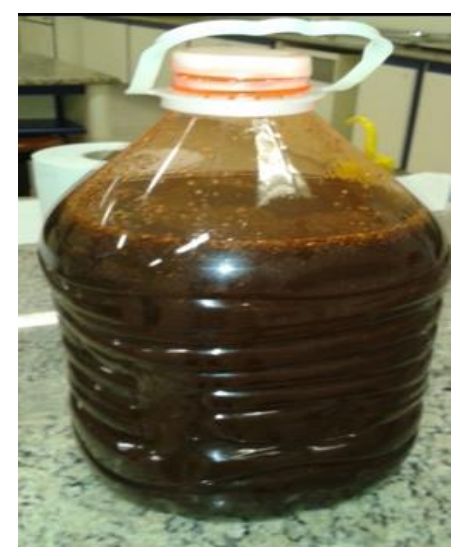

Figura 3: Óleo residual da fritura.

\subsection{Processo de secagem do óleo}

A produção de biodiesel foi realizada em pequena escala, tendo como consideração os métodos analíticos aplicados por CHRISTOFF (2007), determinando a qualidade do material produzido, e consequente produção de um subproduto, a glicerina. Inicialmente, o óleo passou por uma filtragem com o auxílio de uma peneira para retirada de materiais particulados presentes no óleo de fritura. Logo após a filtragem, realizou-se o processo de secagem do óleo bruto devido aos alimentos congelados liberarem água durante a fritura. No processo de secagem, pesou-se $300 \mathrm{~g}$ do óleo bruto em um béquer de $500 \mathrm{~mL}$ e sob aquecimento e agitação, adicionou-se $14 \mathrm{~g}$ de Cloreto 
de Sódio $(\mathrm{NaCl})$ até sua dissolução parcial. A mistura foi transferida para um balão de separação para a decantação do excesso de cloreto de sódio, que foi retirado do processo.

\subsection{Reação de transesterificação para a produção de biodiesel}

A síntese do biodiesel foi realizada a partir do processo de transesterificação com metanol, na presença de hidróxido de sódio.

Para a produção de metóxido de sódio, dissolveu-se em um béquer de $250 \mathrm{~mL}, 1,7 \mathrm{~g}$ de hidróxido de sódio $(\mathrm{NaOH})$ em $50 \mathrm{~mL}$ de metanol, com auxílio de um agitador magnético e controle de temperatura $\left(60^{\circ} \mathrm{C}\right)$ até total dissolução.

Realizou-se a reação de transesterificação em um aquecedor com agitação magnética. Em um béquer $500 \mathrm{~mL}$, adicionou-se $150 \mathrm{~mL}$ do óleo usado em frituras medido em uma proveta. Aqueceu-se o óleo sob agitação com o auxílio de uma barra magnética, até atingir a temperatura de $60{ }^{\circ} \mathrm{C}$. Em seguida, adicionou-se a solução de metóxido de sódio já preparada, mantendo a mistura por 15 minutos a $60{ }^{\circ} \mathrm{C}$ sob agitação. Houve uma mudança no aspecto da solução com mudança de coloração.

Após o término da reação, transferiu-se a solução para um funil de separação, onde ficou decantando durante 24 horas para a separação total das fases: a fase superior contendo o biodiesel e a fase inferior contendo glicerina. Em seguida, recolheu-se a fase inferior em uma proveta de 100 $\mathrm{mL}$. O biodiesel foi transferido para um béquer de $250 \mathrm{ml}$, onde se ajustou o $\mathrm{pH}$ utilizando uma solução de $\mathrm{HCl}$ 0,1 mol/L. Após esta etapa, fez-se uma nova separação em funil de decantação, adicionando-se $\mathrm{NaCl}$ para posterior secagem. Separou-se uma alíquota da amostra, que foi utilizada para as análises de identificação do combustível. A figura 4, mostra o biodiesel em um funil de separação (fase superior), onde a fase inferior é o $\mathrm{NaCl}$ utilizado para secagem.

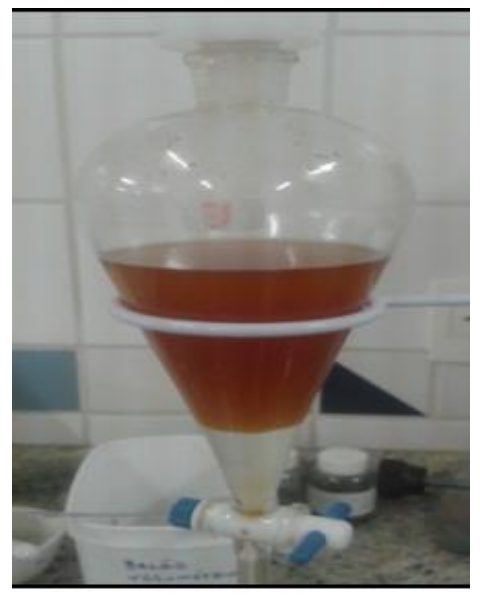

Figura 4: Biodiesel após purificação 


\section{RESULTADOS E DISCUSSÃO}

\subsection{Análises Laboratoriais}

Foram realizadas análises de laboratório para estabelecer parâmetros comparativos do biodiesel obtido no experimento com os dados de literatura. As análises realizadas foram densidade e ponto de fulgor.

A densidade da amostra de biodiesel de nosso experimento foi de $878 \mathrm{Kg} / \mathrm{m}^{3}$, valor coerente dentro da especificada na resolução da ANP 07/2008 (FERREIRA e CRUZ, 2009), que é de 850 $900 \mathrm{Kg} / \mathrm{m}^{3}$. O ponto de fulgor obtido foi $185^{\circ} \mathrm{C}$, valor também próximo ao mínimo especificado na literatura que é $170{ }^{\circ} \mathrm{C}$ (FERREIRA E CRUZ, 2009).

\subsection{Cromatografia gasosa}

Realizou-se a análise cromatográfica como método analítico qualitativo, ou seja, apenas para evidenciar a presença de ésteres metílicos. Segue abaixo os resultados das análises cromatográficas conforme a figura 5, que mostra o perfil de uma amostra padrão de ésteres metílicos dos ácidos graxos e a figura 6, que representa o cromatograma da amostra de biodiesel produzida no experimento:

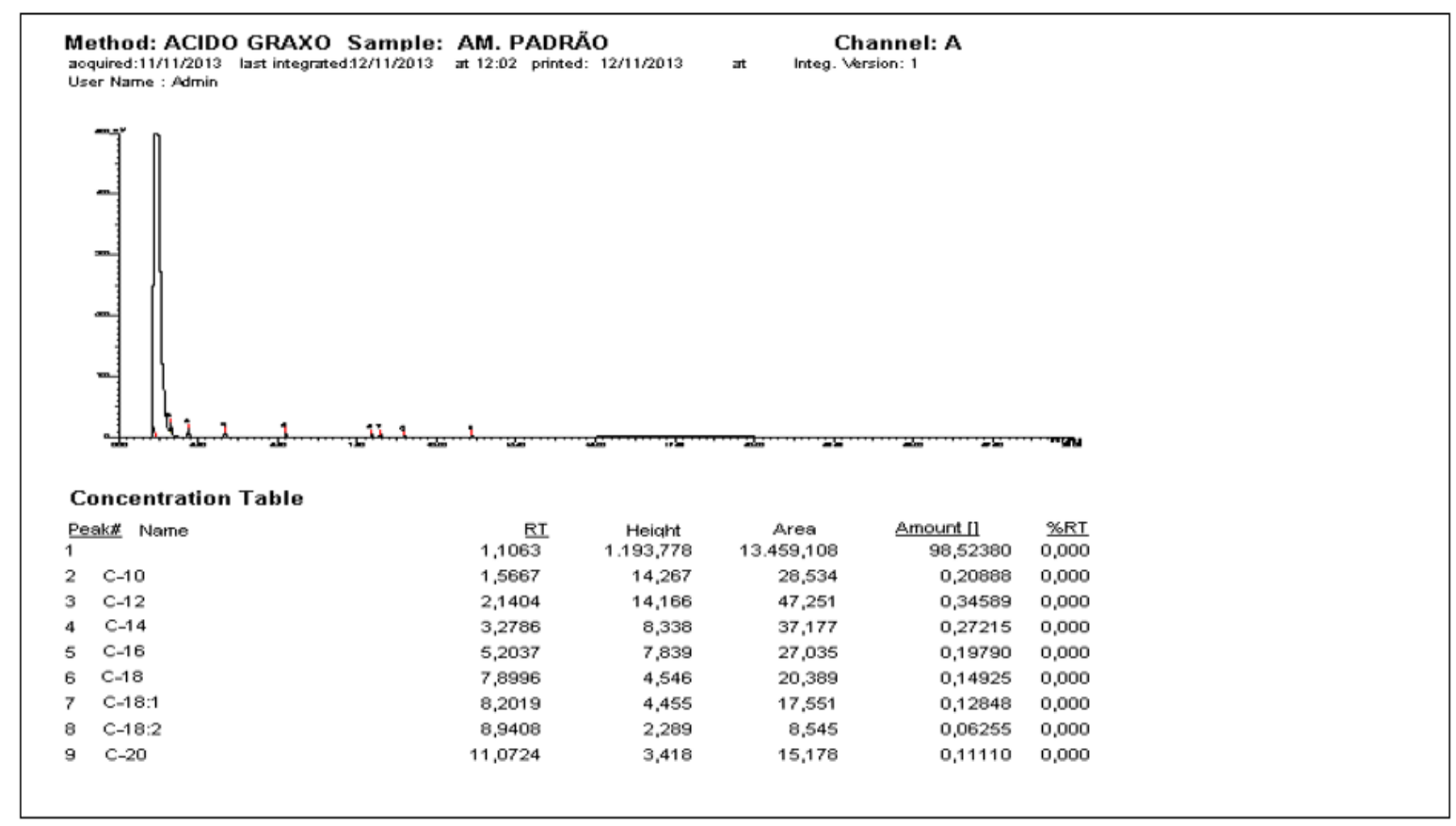

Figura 5: Amostra padrão dos ésteres metílicos de ácidos graxos 


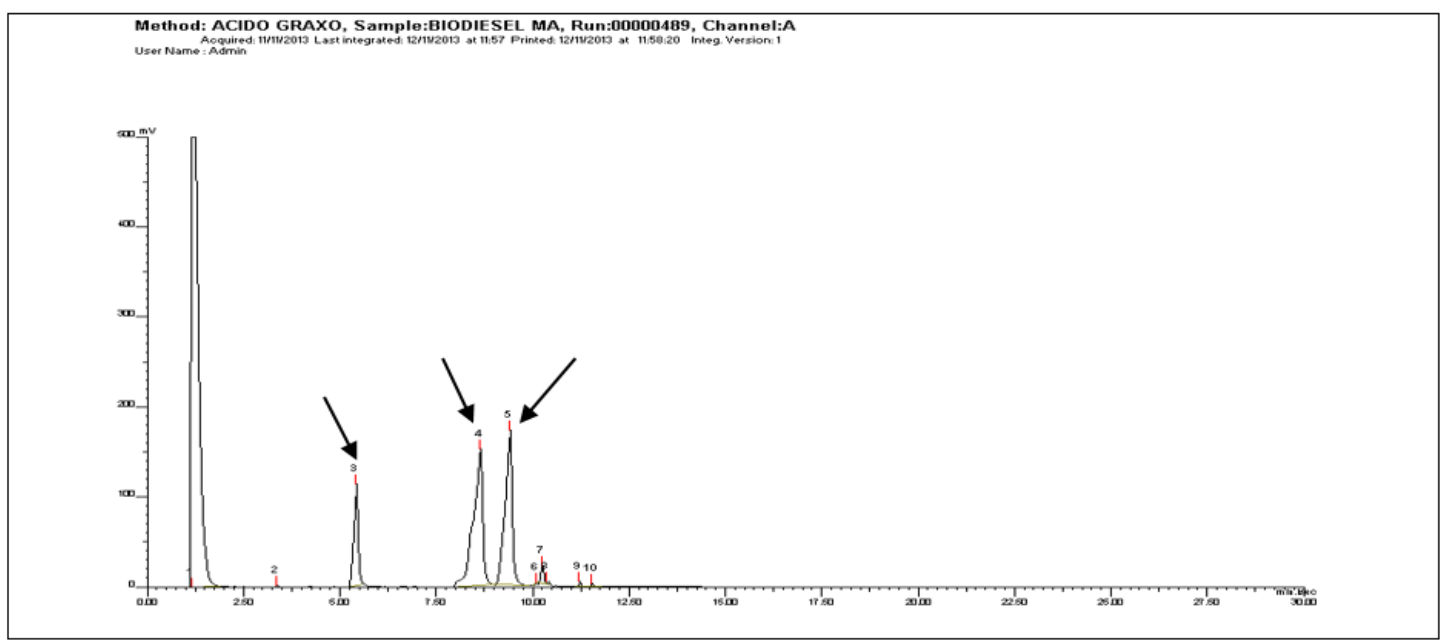

Figura 6: Cromatograma do biodiesel produzido no experimento.

Através da figura 6 observamos picos semelhantes ao perfil da amostra padrão. Os picos assinalados indicam a presença de C16 - Palmitato de metila, C18:1 - Oleato de metila e C18:2 Linoleato de metila característicos de biodiesel de óleo vegetal (picos 3, 4 e 5 respectivamente). Desta forma concluímos que a reação de transesterificação ocorreu dentro do esperado.

\section{CONCLUSÃO}

A partir das análises efetuadas, pode-se concluir que o biodiesel foi obtido com sucesso em escala laboratorial, contemplando a proposta inicial do projeto. Os produtos biodiesel e glicerol formaram um sistema bifásico bem definido, que facilitou a separação das fases. A análise cromatográfica mostrou a presença dos principais ésteres metílicos dos ácidos graxos presentes em uma amostra de biodiesel, caracterizando o produto em questão. Esta conclusão foi reforçada pelos valores de densidade e ponto de fulgor, dentro dos parâmetros esperados para um biodiesel comercial.

\section{REFERÊNCIAS}

BILCK, A. P., SILVA, D.L.D., COSTA, G.A.N., BENASSI, V.T., GARCIA, S. Aproveitamento de subprodutos: Restaurantes de Londrina. Revista em Agronegócios e Meio Ambiente, v.2, n.1, p. 87-104, 2009.

CHRISTOFF, Paulo. "Produção de biodiesel a partir do óleo residual de fritura comercial, estudo de caso: Guaratuba, litoral paranaense". LACTEC-Instituto de Tecnologia para o Desenvolvimento. Dissertação de Mestrado, p. 82, Curitiba, 2007.

DIAS, L. A. S. et al. Cultivo do pinhão manso (Jatropha curcas L.) para produção de biodiesel. 1.ed. Viçosa: UFV, 2007 
FERREIRA, S. L. C. e CRUZ, R. S. Biodiesel: Parâmetros de qualidade e métodos analíticos. Quim. Nova, v. 32, No. 6, p. 1596-1608, 2009.

LIMA, P.C.R. O biodiesel e a inclusão social. Consultoria Legislativa. Brasília: Câmara dos Deputados. 2004.

NOGUEIRA, G. R. e BEBER, J. Proposta de metodologia para o gerenciamento de óleo vegetal residual oriundo de frituras. Disponível em:

http://www.unicentro.br/graduacao/deamb/semana_estudos/pdf

PARENTE, E. J. S.. Biodiesel: Uma aventura tecnológica num país engraçado. Fortaleza: Unigráfica, 2003.

PIGHINELLI, A. L. M. T. Extração mecânica de óleos de amendoim e de girassol para produção de biodiesel via catálise básica. Dissertação (Mestrado em Engenharia Agrícola) - Universidade Estadual de Campinas, São Paulo, 2007.

SOLOMONS, T. W.; Química orgânica 2, Rio de Janeiro, 7 ed. Editora LTC, 2002. 